\title{
Tribal Governance: The Business of Blockchain Authentication
}

\author{
Gianluca Miscione \\ University College Dublin \\ gianluca.miscione@ucd.ie
}

\author{
Rafael Ziolkowski \\ University of Zurich \\ ziolkowski@ifi.uzh.ch
}

\author{
Liudmila Zavolokina \\ University of Zurich \\ zavolokina@ifi.uzh.ch
}

\author{
Gerhard Schwabe \\ University of Zurich \\ $\underline{\text { schwabe@ifi.uzh.ch }}$
}

\begin{abstract}
The blockchain technology offers a novel mode of distributed authentication, which does not depend on a central authority. We consider this novelty against established governance modes. We illustrate our argument by paying special attention to blockchain-based authentication functions in the empirical domain of land registries across the world. Based on interviews with representatives from organizations deploying blockchain, and content analysis of related grey literature, we discuss established governance idealtypes against what the rivalry that cryptocurrencies and blockchains bring to digital settings. After referring to market, hierarchy, network, and bazaar, we conclude outlining the prospects of a different, blockchain-related governance mode called 'tribal' that better captures the 'togetherness' which rivalry originates.
\end{abstract}

\section{Introduction}

If one copies and distributes music, it is still music. If one can copy and distribute money, it is not money anymore. Cryptocurrencies like Bitcoin proved at scale blockchain functionalities, which introduce rivalry into digital environments via distributed authentication. This capacity of authentication is relevant for governance purposes because it introduces a sense of togetherness due to shared interest. This is different from other information goods and the organizational forms they brought about.

Rather than grounded theorizing, or taking its move from existing blockchain literature - which is reviewed in the following paragraph - this article aims at problematizing the well-established typology of modes of governance initiated by Williamson [1] and Powell [2] on the basis of the emerging phenomenon of blockchains. More precisely, the bazaar governance [3], which formalizes digital governance defined by openness and nonrivalry of information goods and exemplified by free and open source software (FOSS), is considered under the light of blockchain architectures and their consequences in use. We argue that the bazaar misses relevant aspects of blockchain-related phenomena. On the basis of this mismatch and illustrations from empirical domains, we propose a different mode of governance which we name 'tribal'. The reference to tribes accounts both for a mode of governance not defined by the rule of law, and for the togetherness that rivalry introduces into the open and common pastures of digital fields.

In the research domain about governance through IT, as distinct from governance of IT, this paper looks at the former and takes a narrow focus on authentication. $\mathrm{Au}-$ thentication is here intended in its basic meaning of certification of genuinity. Against the background of information openness and abundance, typical of open information infrastructures, we claim that the major information management innovation introduced by blockchain - and proved viable at scale by Bitcoin - is distributed authentication. We illustrate it relying on cases of actual implementations for land registration.

In open networks like the internet, the governance problem is at the fringes. Since there is no way to seal boundaries to define who is in and who is out, then to control them, open networks are constantly exposed to malicious actors. So, openness is generative both of innovations and misconducts [4]. This polarization depends on architectural openness and on nearly zero marginal cost for replication and distribution, which in turn made IT unsuitable for native digital money (i.e. without external and non-digital guarantor). That is because, of course, money must not be replicable (i.e. counterfeitable).

The blockchain circumvents this limit of IT and brings rivalry into the digital environment. It proved rivalry viable by making transactions public and by letting the $51 \%$ of computing power (there are alternatives) to authenticate honest transactions. In practice, Bitcoins (or tokens more generally) cannot be replicated because authenticated transactions locate any token and differentiate it from any other. From another angle, Bitcoin tested at scale a rewarding mechanism for keeping faceless and globally dispersed actors honest when operating on this open network. For such reasons, open (often referred to as 'permissionless') blockchains are particularly interesting for governance issues: they promise to scale easily for positive network externalities, but they are difficult to manage because of lack of both formal organizational structures and boundaries to police.

We place our interest in governance through blockchain against the broader background of progressive decoupling of formal organizations and large information systems (or information infrastructures). For instance, cloud computing has taken the control on IT out of IT departments' hands. Regarding blockchain, this move is well exemplified by the independence of cryptocurrencies from nation-states and central banks.

To support the claim for a new governance mode brought to the fore by blockchain implementations, the remainder is organized as follows: first we identify the cornerstones of our theoretical framework. It takes its moves from studies on IT governance, then presents the bazaar as a recent extension of the well-established modes of governance typology by Powell [2]. We discuss the peculiarities that blockchain introduces against 
these established idealtypes, with a special attention for the bazaar. In particular, we highlight how the rivalry that blockchains introduce into digital environments originates a level of 'togetherness' among blockchain users that does not manifest in information goods and native digital organizing modes like FOSS. Then, after presenting the main works on actual implementations of blockchains, we outline our research methodology. The paper continues with an illustration of blockchain implementations in the domain of land registries. In conclusion, we discuss a mode of governance, which we name 'tribal', that may better account for digital organizing when rivalry plays a relevant role.

\section{Theoretical Framework}

As anticipated, the new architecture introduced and tested at scale by Bitcoin is about authenticating transactions, thus certifying the reliability of it as a public ledger. From another perspective, blockchains introduce rivalry in the online domain: to avoid the double-spending problem, each token of a currency must be identifiable and owned by someone and not anyone else at the same time. The opening example clarifies: if I pass a music file on to someone else, we both can listen to it and it remains music. Instead, if we both can own the same bitcoin, it would not work as money anymore.

The digitally native way of authenticating something introduces rivalry and constitutes a qualitative shift in digital environments. Copies are not all the same as they used to be. This is fostered by the open nature of the Bitcoin blockchain where no single node can be held accountable due to its distributed nature $[5,6]$. Traditional jurisdictions thereby may act as a mediating entity in case of disputes only to the extent concerned parties accept it. Since jurisdictions have never been intended as a service to use as one pleases, basic questions about what social contract underpins blockchain organizing forms are legit to ask [7].

The term IT Governance has been used since the early 1990s [8, 9] and became more prominent later in the decade [10], [11], [12]. Later, IT governance was defined by Weill and Ross [13] as the framework for decision rights and accountabilities to encourage desirable behavior in the use of IT. In Weill and Ross's [13] framework, political idealtypes are used to describe how people in the enterprise make key decisions. Their quite articulated conceptualization is too precise, thus inflexible, to be applicable to blockchains, especially permissionless, which remain in constant flux, do not have actors in the position of fully exercising decision rights, nor clear mechanisms and rules to achieve objectives (a clear example is the never-ending unruly conflict about Bitcoin blocksize). So, while we maintain our focus on IT and governance, we need to move to theories that relate more to actual use.

The recent book by Musiani et al. [14] looks at social and political sciences to account both for the elusiveness to control that the Internet and the services based on it showed to traditional decision makers, and for new ways power is being exercised through IT. The spectrum of positions about IT and governance is wide and spans from traditional managerial command and control approaches to international anarchy. Such diversity suggests that there are basic differences about the understanding of what IT are and how to govern through them. So, we turn our attention to a classic of organization studies: Powell [2], in order to introduce and problematize the 'bazaar governance' [3].

\subsection{From Hierarchy to Bazaar Governance}

According to Williamson [15] "governance is a means by which to infuse order in a relation where potential conflict threatens to undo or upset opportunities to realize mutual gains". Williamson's $[1,15,16]$ core theoretical stance is that transactions entail uncertainty about their outcome, due to the bounded rationality and opportunism of agents. Thus, and as a means of reducing transaction costs, agents implement a governance structure, which Williamson defined as "the explicit or implicit contractual framework within which a transaction is located" quoted in [3]. This line of thinking is expanded by Watson et al. [17] who discuss it in digital domains, with an argument consistent to Surowiecki [18] 'Wisdom of the Crowds', informed by cases like FOSS, Wikipedia and the likes.

As summarized in table 1, hierarchy refers to formal organizations within which command lines and responsibilities are defined and stable. Market refers to atomic actors who freely trade. As Williamson [16] put it: "firms are islands of planned co-ordination in a sea of market relations." Powell [2] picked on this dichotomy and argued that market logics may operate within hierarchies (incentives, for instance) and hierarchies onto markets. So, he proposed the network as a new idealtype, which is most suited to domains where measurements are difficult and trust among parties has a paramount role.

Demil and Lecocq's [3] study proposes to add a fourth idealtype, named 'bazaar governance', to Powell's [2] tripartite categorization of governance forms. Their work, based on FOSS production, found that Powell's threefold characterization was not satisfactory to explain the then booming phenomenon of FOSS, and by extension the information economy, so they proposed the bazaar idealtype.

FOSS took the hegemony over the internet not only by ignoring much of the received wisdom about IT governance, but also projecting the possibilities of open collaboration beyond software development. For instance, voluntary geographic information (and user-generated content more broadly) has shown that formal expert organizations are not the only way of getting things done; consumer electronics and open internet services have replaced business technologies in leading the ways of innovation; crowdfunding has unveiled the blindspots of traditional investors' preferences. 
Table 1. Governance idealtypes adapted from Powell [2] and Demil and Lecocq [3]. The last column in italics on the right is an anticipation of our proposal for a novel governance idealtype which we named 'tribal'. It is discussed in the last part of this paper.

\begin{tabular}{|c|c|c|c|c|c|c|}
\hline Features & Explanation & Market & Hierarchy & Network & Bazaar & Tribal \\
\hline $\begin{array}{c}\text { Contract } \\
\text { Framework }\end{array}$ & $\begin{array}{l}\text { Legal framework for } \\
\text { transaction }\end{array}$ & $\begin{array}{l}\text { Classical } \\
\text { contract }^{1}\end{array}$ & $\begin{array}{l}\text { Employment } \\
\text { contract }\end{array}$ & $\begin{array}{c}\text { Neoclassical } \\
\text { contract }^{2}\end{array}$ & $\begin{array}{l}\text { Open license con- } \\
\text { tract }\end{array}$ & $\begin{array}{l}\text { (Until now) Post-hoc: a } \\
\text { record if/when needed }\end{array}$ \\
\hline $\begin{array}{l}\text { Coordination } \\
\text { Mechanism }\end{array}$ & $\begin{array}{c}\text { Means of governing } \\
\text { exchanges }\end{array}$ & Price & $\begin{array}{l}\text { Formal line } \\
\text { of authority }\end{array}$ & $\begin{array}{l}\text { Embedded } \\
\text { relations }\end{array}$ & Product & $\begin{array}{c}\text { Adherence to the technical } \\
\text { protocol }\end{array}$ \\
\hline $\begin{array}{l}\text { Normative ba- } \\
\text { sis }\end{array}$ & $\begin{array}{l}\text { Main regulatory } \\
\text { force }\end{array}$ & $\begin{array}{c}\text { Market } \\
\text { exchanges }\end{array}$ & Forbearance & Exchanges & $\begin{array}{c}\text { Openness and fair- } \\
\text { ness }\end{array}$ & Consensus-based \\
\hline $\begin{array}{l}\text { Identity of par- } \\
\text { ties }\end{array}$ & $\begin{array}{c}\text { Degree to which } \\
\text { identity of parties } \\
\text { matters }\end{array}$ & Irrelevant & Irrelevant & Relevant & Partially relevant & Pseudonym-based \\
\hline $\begin{array}{l}\text { Nature of in- } \\
\text { centives }\end{array}$ & $\begin{array}{l}\text { Incentives for trans- } \\
\text { acting parties }\end{array}$ & $\begin{array}{l}\text { Competi- } \\
\text { tion }\end{array}$ & Status & Reciprocity & Reputation & $\begin{array}{c}\text { Hoarding (for currencies) } \\
\text { Reliability (for records) }\end{array}$ \\
\hline $\begin{array}{l}\text { Incentives In- } \\
\text { tensity }\end{array}$ & $\begin{array}{l}\text { Agent's motivation } \\
\text { to contribute }\end{array}$ & High & Low & Intermediate & Low & High \\
\hline $\begin{array}{l}\text { Control Inten- } \\
\text { sity }\end{array}$ & $\begin{array}{l}\text { Capacity to enforce } \\
\text { regulations }\end{array}$ & Low & High & Intermediate & Low & $\begin{array}{l}\text { Low from the outside } \\
\text { Intermediate from inside }\end{array}$ \\
\hline
\end{tabular}

These peculiarities of digital governance are formalized by Demil and Lecocq, who relied on the initial ideas by Raymond [19]. Indeed, the label bazaar derives from Raymond's [19] work who contrasted it to the traditional approach to software development, likened to a 'cathedral'.

The bazaar mode of governance is defined by open licenses, which allow unrestricted access to the source code and prevent anyone to appropriate and trade on software ownership. This reduces substantially the transaction cost of FOSS. The consequent governance mode is based on openness and transparency: software developers build up their reputation, which they can then spend providing assistance on the software they know [20]. Overall, like in a bazaar, both direct incentives and controls are low. In fact, the bazaar clearly differs from hierarchies because there are no defined organizational structures along which command and control lines can be used to regulate behaviors. It also differs from markets because open source licenses do not grant anyone with exclusive ownership rights, thus software cannot be traded as a commodity for direct profit. Finally, it differs from networks because membership and associations are fluid, and selection does not happen at the entry points.

Since their study pinpoints to some peculiarities of digital organizing, we thought of studying to what extend the bazaar helps explaining another rapidly emerging phenomenon: blockchains. We found strengths and weaknesses. In the first place, we find that their focus on transaction cost and copyleft as a peculiar kind of contract are reductive. Rivalry and trust appear, respectively, more prominent.

\footnotetext{
1 Based on Demil and Lecocq [3]: In classical contract law, transacting parties identity is irrelevant and their dependence slight.
}

\subsection{Authentication and Rivalry}

Like any other FOSS project, the source code of most blockchain software is publicly available for anyone to check, use, develop and redistribute it. In spite of these apparent similarities, there are remarkable differences between open-source applications like web browsers or word processors and blockchains. Blockchains, by authenticating some data against the rest, introduce rivalry to the digital environment, which has always been characterized by infinite replicability, thus plentitude. In short, before the blockchain, all copies were the same. With blockchain it has become possible to differentiate something from something else (like who owns a bitcoin) without relying on non-digital authorities. This property of the blockchains underneath cryptocurrencies is allowing to move from openness and gift economy, well exemplified by FOSS, to a digitally native economy, at the expenses of the non-rivalry that used to characterize information goods. This establishes a novel link between distributed authentication and modes of governance.

Concretely, if at some point any open source web browser users is dissatisfied with the software, they can decide to fork the code and develop an independent version to fit their own and new users' preferences. When this happens, users of both versions maintain the capacity to use their software for most if not all browsing purposes. This is not the case with blockchains, whose main purpose is to guarantee the authenticity of the data they gather. When a fork takes place, data on the forked ledgers may differ and the reliability they offer be hampered [21].

To clarify this point, let us consider the most developed blockchain: Bitcoin. All Bitcoin transactions are authenticated and recorded on one public ledger maintained by all miners. Because of the increasing

\footnotetext{
2 Further [3]: In neoclassical contracts, hybrid organizations remain autonomous but bilaterally dependent and their identities matters.
} 
number of Bitcoin transactions, the blockchain manifested bottlenecks in authenticating all of them in a timely fashion. Some developers have proposed solving this problem by modifying the software to increase the blocksize, but the miners who were making money out of the high transaction costs granted by the status quo, opposed it. Unlike with the web browser example, this is where Bitcoin manifests a substantive mismatch with the bazaar idealtype: miners have a prominent role in maintaining network integrity and reliability, so they have unprecedented power. Indeed, the fork of the software, which happened in August 2017, created two distinct blockchains each one maintained by different miners. Bitcoins attached to one cannot be traded on the other any longer. Whereas a forked browser is usable for the whole Web. So, while forked browsers retain their use value quite independently from the fork size, Bitcoin use value depends on mining capacity and trade mass. Hence, compared to FOSS projects, public distributed ledgers show a level of togetherness that affects all involved actors (end users, miners, companies, regulators, etc.). This togetherness is more defining than open licenses, which define the bazaar idealtype.

These differences from FOSS are explained by the actors involved and the rules governing their relationships. Bitcoin involves a number of significant players that together guarantee its blockchain consistency across time and space. First, a relatively small group of core developers is responsible for new code; this is common to FOSS. Second, a relatively large number of miners authenticate transactions so they are properly executed and no double spending is allowed. Then, there are the many users who trade in Bitcoin and may have little knowledge or interest into its underlying functioning. Still, by trading fiat money for Bitcoins, they affect massively its valuation level, thus the financial incentives for everyone involved. Therefore, even if copyleft licenses are adopted for blockchains, they are not as determinant for governance as Demil and Lecocq [3] claim they are for other FOSS projects.

Secondly, the centrality that Demil and Lecocq [3] accord to transaction cost economics does not seem to explain relevant aspects of blockchains. Starting from Williamson [1], Demil and Lecocq [3] pose central attention onto the transaction cost economics, which discriminates between market and hierarchy. Even though from other empirical domains, studies like Lucas and Goh [22] as well as Garud and Munir [23] pose doubts on emphasizing transaction cost. Trust was argued to be central in networks and bazaar. In spite of recurrent references to trustless transactions, we see trust as central for blockchains as well. This is explored in the following paragraph.

\subsection{Faceless Trust}

Both the network and the bazaar modes of governance exceed the hierarchical and market modes of regulation and are explanatory of cases where trust plays an important role. Trust is given paramount relevance in Powell's networks as the glue that guarantees reciprocity. Trust is a key factor and is also described as the primary governance mechanism for dyadic or network exchange relationships [2]. Trust does not only minimize transaction costs, but also creates value (with enhanced information sharing) for such relationship [24]. The reputational nature of bazaar incentives works only to the extent participants trust a fair allocation of resources down the line.

Rivalry might make think that actors do not trust each other, nor the whole system. This stance is misleading. It is not uncommon to read claims that blockchains are trustless. This proves quite narrow if one considers that no one is forced to use blockchains. So, users and/or organizations do trust them to the extent they use them, including pouring real money. In permissioned blockchain trust is, at the very least, posed in those who are in charge of policing the access points. Having said that, it is reasonable to accept that blockchain introduces a way to trade without intermediaries with unknown people, whom we may not trust individually. This is what we call faceless trust.

We turn to Gambetta's [25] formalization of the concept of trust, quoted by Lustig and Nardi [26], to conceptualize it as a central concepts for blockchainrelated governance. According to him, trust is the subjective sense that one has about another performing a particular course of action, with consequences for the former, without being monitored. Trust is, therefore, there to bridge over the uncertainty about the future [27]. Trust in authenticity of transactions reduce the reliance on traders' subjectivity.

Although trust appears central for blockchains, there are no studies yet that focus on the mutual relations between blockchains and trust. Blockchain technology refers to transfer of trust from offline to online domain, or to the emergence of trustworthy relations where there were none or weak. In contrast to classical way of perceiving trust in online relationships [28], trust in blockchain technology does not require thirdparty guarantees or any third party at all. Therefore, blockchain-enabled trust can be seen as faceless, meaning that there is no actor who plays the role of a trustee. The tribal governance mode we propose offers a framework for future studies in this direction.

\section{Current Research on Blockchain in Use}

In recent years, Bitcoin first and blockchains later have attracted wide-spread interest [31]. Of course, computer scientists have been first movers to approach this emerging phenomenon and proposing many variants of the architecture concept outlined by Nakamoto [32]. In defining this literature review, we were interested in blockchains in actual use, not in publications outlining the potentials of this new architecture, or possible improvements. Since empirical studies are still sparse, our selection criterion left us with a relatively small number of works to consider: not least because of the long-time cycle of implementing IT, studying it, 
and going through peer-review processes, we could not find much academic literature based on studies of actually implemented and used blockchains in real-life settings. Consequently, despite our keen intention of differentiating between speculations about the potentials of blockchain and actual uses, it was often difficult to discriminate between what was aimed at by designers and researchers from what was happening in practice.

Utilizing blockchains comes with the trust, or just the assumption, in algorithms and their capacity of governing organizational relations. Along this line, Lustig and Nardi [26] dive into the Bitcoin phenomenon to investigate how algorithms have gained authority and legitimation in directing human activities by defining what information we rely upon. They criticize, like Dodd [33] does, the emic views of people promoting Bitcoin for their naive assumptions about technological neutrality and independence from allegedly corrupted politics. A similar approach can be seen in the discussion on blockchain-based state governance $[34,35]$. Even if we agree that algorithms are not neutral in transforming human behaviors, organizations, and societies, we find that a narrow focus on algorithms does not account for novel aspects that blockchains bring to the fore. Thus, this article takes a different starting point: the rivalry that the blockchain architecture introduces by means of authentication, which miners maintain, and users rely upon and reinforce by using blockchains. Indeed, if we considered algorithms solely, we would not see much difference between open source software and blockchains, and the authentication they bring about by relying on miners and traders. This distinction is expanded upon later, when limits of the bazaar idealtype are discussed and tribal governance introduced.

Studies about governance often discuss issues of jurisdiction, which remains uncertain here because the responsibility for the genuinity of transactions has shifted to allegedly independent miners or other consensus methods, which are located outside of formal organizations' and jurisdictions' reach, which, therefore, are not easy to be held accountable [36]. As a consequence, legal uncertainty in transactions increases. A way to mitigate this uncertainty are so-called smart contracts, which gained popularity as well as controversy.

Traditional contracts reduce uncertainty by committing all signatories, who remain subject to the rule of law. But blockchain may exceed jurisdictions, thus fall in the cracks between inconsistent jurisdictions. Dupont and Maurer [37] reflect on the applicability of smart contracts and their relationship to law. It is claimed that distributed, autonomous, and self-executing contracts are not feasible due to their non-contractual basis. Durkheim argues: "Wherever a contract exists, it is subject to regulation, which is the work of society and not of individuals". Smart contracts are not contracts, they are rather automatisms built on the top of blockchain authentication [37]. Even if there is a growing interest for smart contracts, we marginally consider them here since they are envisioned as a layer on the top of blockchains.

Morabito et al. [39] offer the most exhaustive overview of the state-of-the-art of blockchain in organizations. The salient cases presented there are Coinbase, Everledger, Factom, eHealth and electricity management applications, finance and smart-contracts. Those case-studies were useful to us navigating and putting in perspective materials about the actual implementations we found, and to decide who to contact directly. Interestingly, blockchain architecture is believed to fit into fundamentally different domains in terms of scope or transactional volume: from land registries to supply chain management systems, from intellectual property right management to money transfers and payments. In all those domains, the incumbents are intermediaries or third-party guarantors, which the blockchains aim at substituting.

Walsh et al. [38] conducted a literature review to gain an overview of blockchain characteristics, a necessary step to define blockchain types. Key blockchain characteristics are: level of permission, restriction of public access to data, modes of consensus, modularity, scalability, interoperability, anonymity. Four possible types emerge: Decentralized/Extensible (Bitcoin), Decentralized/Inextensible (Counterparty), Centralized/Extensible (Ripple), and Centralized/Inextensible (R3). Empirical investigation is expected to uncover a number of operational issues associated with different types, e.g. issues of governance, political aspirations, control, risk and resistance to change from those continuing to use traditional systems.

We could group other contributions according to their focus on public services or private sector. From the former, a case study in healthcare by Ekblaw et al. [40] analyzes MedRec, a system that gives patients a comprehensive, immutable log and easy access to their medical information across providers and treatment sites. Leveraging a blockchain, MedRec manages authentication, confidentiality, accountability, and data sharing, all crucial considerations when handling health data.

In the private sector, certainly the most developed domain is finance, not least because of the Bitcoin experience. Morisse [41] surveys 42 papers about cryptocurrencies in terms of methods, concepts, and approaches and finds that cryptocurrencies had not reached IS research, at least in 2015. Studies on security were more receptive of this emerging phenomenon. Herbert and Litchfield [42] research the application of property rights in the case of blockchain-based software piracy prevention. Karame et al. [5] analyze the probability of double-spending on the Bitcoin blockchain and claim that the current Bitcoin log does not provide sufficient information to provide sufficient accountability, which would facilitate to blacklist malicious nodes.

Overall, Morabito et al. [39] warns about the risks of privatizing state functions through blockchains as 
they contribute to "a process of undermining public institutions, the superiority of economics over politics, and the change of citizens into to customers (...), which perpetually empowers markets to the disadvantage of citizens", which is in line with Atzori [34].

\section{Method and Data Collection}

Blockchain is a new technology and only recently it has started to become applied outside the cryptocurrencies domain. Thus, it is time now to explore new phenomena emerging when blockchains are being applied to societal and business problems. Blockchain governance is such a new phenomenon. It is time to check whether old models of how business is conducted, organized and governed appropriately describe and explain blockchain-related governance. For this matter, we reviewed related research with empirical components, categorized blockchain-based companies in their intentions to use blockchains, and conducted semi-structured expert interviews to consequently derive blockchain governance characteristics and to contrast them to governance idealtypes.

As typical for exploratory research [43, 44], we used all available sources to uncover interesting phenomena and derive appropriate concepts to describe them. Specifically, we reviewed the still scarce, but rapidly growing scientific body of work for reports on blockchain governance, alongside scanning more than six hundred sources for related materials obtained from the blockchain research project Coding Value, as well as research databases and search engines such as Scopus, Web of Science, and Google Scholar among others. We utilized various search strings consisting of 'blockchain' and 'governance' to ensure a wider coverage of research domains, such as organizational and social sciences. This initial step serves as a precondition to frame Powell's and Demil and Lecocq's classification of governance idealtypes and research on blockchain governance characteristics from an academic standpoint. All publications without reference to blockchains in use have been disregarded because outside of the scope of this work.

To complement our literature review from an academic side with practitioner's intention to use blockchains, we also analyzed 126 blockchain-based companies from a variety of online sources like Crunchbase and Coindesk for their governance characteristics. Identifying relevant cases has proved a difficult task because of the novelty of this domain and the hype that wraps it. Indeed, there are countless startups, initiatives, GitHub projects, but few running implementations, which also causes empirically grounded research to be scarce. In sum, our data collection is based on papers, practitioners' reports, grey literature, specialized press, blogs, as well as insights we gained from expert interviews.

Through our search for blockchain-based companies, we found the most advanced application domains to be (1) financial solutions, like wallets and payments,
(2) digital identity of legal persons or tangible as well as non-tangible assets, and (3) infrastructure provision of data and transaction storage. In more detail, supply chains, intellectual property rights, land registries, and micro transactions are those areas where applications have been released to "the wild". While we have systematically studied a total of two dozen applications in four domains, space restrictions allow us only to describe the domain of land registries in this paper. Here, we complemented a review of practitioner-based literature with interviews with high tier executives.

Scientific publications, practitioner's reports, and the interview data were fed into an iterative sense-making process: the authors coded and conceptualized the information individually. Codes were initially seeded by using concepts characterizing established governance mechanisms (i.e. market, hierarchy, network, bazaar). These individually gathered insights were then discussed by all authors. We also exposed immediate results and sought for input from the Coding Value research project. This input was then used to revisit the data and further develop our concepts. The highest level conceptual results is depicted in table 1 above, where we contrast established governance mechanisms with tribal governance. This iterative approach was finished when theoretical saturation was reached.

\section{Blockchain-based Land Registry}

In the following, we present the business of authentication in the real-life domain of land registries. Land registry received attention at the World Economic Forum [45], especially for the long time-span that they must cover. Table 2 below lists the main cases we found and their main references.

Table 2. Overview of found land registry cases

\begin{tabular}{ccc}
\hline Case & Location & References \\
\hline A & West Africa & {$[46,47]$} \\
\hline B & Caribbean & {$[48-50]$} \\
\hline C & Scandinavia & {$[51-53]$} \\
\hline D & Caucasus & {$[54,55]$} \\
\hline
\end{tabular}

All these cases officially announced projects to store and transfer records of land ownership via blockchain - some projects are already piloted and being tested (A and C), other states already announced to join (e.g. Dubai). Land registry and transfer of ownership, historically, are perceived as bureaucratic and costly, involving an authorized third party, e.g. notary services and state bodies, to seal those transactions and to maintain the records for generations to come. The bookkeeping often relies on paper-based documentation, which promises longevity and reliability. It comes as no surprise that mostly, but not only, developing countries put a special emphasis on this matter. Land tenure is indeed seen as basic for further economic development, including financializing through collaterals. Assets as lands are both valuable and necessary, thereby lucrative for fraud or corruption. Fraudulent 
renting, expropriations, extortion, and bribery are as well documented as corruption in dealing with governmental or notary third parties $[49,54,56]$.

In the case of A, a country in West Africa, the blockchain project is part of an overall state digitization initiative which aims at creating a novel eco-system, connecting notaries, state, investors, and citizens. Land records ambiguity and corruption have motivated this initiative. Their implementation partner is active in more than five countries and maintains more than one thousand land records at the time of writing. This blockchain-based solution is quite original: it authenticates transactions with proof-of-stake, which is faster and cheaper than Bitcoin's mining-intensive proof-ofwork. It also links its own tokens to both permissioned and permissionless blockchains to leverage their different properties. In practice, to ensure the system's resilience against tampering, each token is linked to Bitcoin blockchain, whose scale guaranties proof-of-existence, and a storage chain, where to save actual records data. Responsible for data entry is a partnership between state authorities and notaries, who can also modify claimed contentious data and thereby acts as a single 'point of truth'. The authentication of records therefore partly relies both on open infrastructures and local actors (both state and private).

Case B targets a prototype in a Caribbean country which can be considered as first-mover in blockchainbased land registry. Consistently with the idea that blockchains may have positive effects where other modes of governance encountered problems, this country has gone through decades of failed land reforms before trying this technology. The World Bank has been active here for decades and this project can be seen a recent development of a long-term international presence. The implementation partner is US-based and applies his offering to various domains beyond land registries, which means that, differently from case A, the solution is less tailored onto the specific application and the social context of use. Same as in case A, record ambiguity and officials' corruption were the main driver for this initiative. Starting with a proof-of-concept in 2015 , the project has been stalled shortly after its announcements due to political issues (reelection) and is currently regaining pace. Similarly, to case A, the state of B remains the 'single point of truth' regarding data entry but it may have easier access to modification of records because all nodes of the permissioned blockchain used, run, at the time of writing, on servers belonging to a single organization. Originally, this blockchain relies on proof-of-burn, which facilitates the control on frequent changes of the records, also traced on Bitcoin blockchain.

The project regarding case $\mathrm{C}$ in Scandinavia started in 2016 and includes the state land registry office, a consultancy, a telecommunications provider, a blockchain-based implementation partner, and financial institutions. Long term national efforts for the digitization of state services have been the main motivation for undertaking land registry and facilitate digital and secure ownership transfers. At the time of writing, the project finished its second test run. From a technical perspective, data entry and changes are decided upon by the state authority in a permissioned blockchain which is embedded in the existing spatial data infrastructure, also comprising the cadaster. The authenticity of records is thereby solely dependent on the state and its infrastructure, in contrast to case $\mathrm{A}$ and $\mathrm{B}$, and does therefore not rely on record maintenance provided by independent miners like Bitcoin blockchain's. The goal to make information available to affiliated, authenticated parties is eased by the utilization of electronic ID's provided by the telecommunication provider, and apparently in conformity to EU regulations.

The state of $\mathrm{D}$, whose territory and sovereignty have been under threat, is known for its e-government efforts especially in collaboration with international agencies. It partnered up in 2016 with a US-based implementation partner in order to increase land record reliability. This implementation shows similar traits as case $\mathrm{A}$ and $\mathrm{B}$, relying on a permissioned blockchain which is anchored to the Bitcoin blockchain using distributed digital timestamping. This might be particularly important in case of occupation. Still, the state, again, remains responsible for these foundational data entry, while the Bitcoin's proof-of-work assures data integrity.

\section{A Proposal for Tribal Governance}

The domains of blockchains applications that we considered (money transfer, intellectual property rights management, supply chain monitoring), and the specific illustration provided above from land registries, show some basic differences between blockchain governance and the bazaar idealtype (also refer to the idealtypes in table 1):

- Contrary to open source licenses that prevent anyone to appropriate the "matter of trade" (i.e. the developed software), public ledgers introduce authentication into digital settings. So we move from 'carrots and rainbows' [20] to rivalry;

- While in FOSS projects the majority cannot enforce its decisions onto everyone, because anyone can fork their own version relying on publicly available code at low cost while preserving their own use value, in blockchain matters majority decisions are enforced and forking poses substantial costs on all users;

- Cryptocurrencies or other built-in blockchain rewarding schemes affect people's involvement not least because they trade and hoard tokens. This is not a feature of other FOSS projects;

- Derived from the previous points, blockchains manifest a level of mutually dependent interest, thus organizational togetherness, that the bazaar idealtype does not accounts for.

The blockchain architecture thereby marks a paradigm shift in two ways: a) from traditional and centralized to digital and (currently) decentralized authentication method, and also b) from a digital gift economy 
to digital-only trades. This is new because before it, one could only rely on credit money or had to do things for free, trusting in a gift economy. A third option, i.e. both digital native and paid directly, is allowed by distributed authentication of transactions, which introduces rivalry in the digital environment. In other words, authentication allows an alternative to the gift economy without having to rely on external guarantors.

While we maintain that digital modes of governance present substantial differences from previous ones, we find the common emphasis on software reductive. The focus on FOSS as main empirical reference for the bazaar governance idealtype is limiting because it overemphasizes the production and development of software over its deployments, actual usages in practice, and remarkable influence that maintainers like miners exercise. Because of their functioning as long term immutable ledgers, blockchains cannot be designed, deployed, maintained, nor understood without considering their actual use and the tensions they generate in real-life settings. Those phenomena manifest only at scale and when real interests are involved.

Lustig and Nardi [26] pose special attention onto algorithms as defining aspect of Bitcoin, whereas we argue that ledger's maintainers and tokens' users are what characterize the governance of blockchain as much as the other governance purposes it can be used for. Indeed, beyond software development, the authenticity of the ledger is what maintainers guarantee and users rely upon. Authenticity is not a straight product of algorithms, but a sustained long-term effort that all involved parties contribute to and depend upon. Beyond software developers, miners (or whoever maintains the ledger) and traders (or whoever uses the tokens for the most diverse purposes) gained a prominent role in governance. These peculiarities (authentication vs. infinite replicability, actual use at scale, long-term timeframe) prompted us to propose 'tribal governance' as a new mode of governance, and to outline its cornerstones.

The broader and distributed resources that tribal governance relies upon and shapes is not accounted for by the bazaar idealtype and its sole focus on production, copyleft, and transaction cost. More precisely, the digitalization of authentication functions usually performed by organizations reveals some limitations of the bazaar idealtype (see also table 1 above):

- Rivalry originates a sense of togetherness which FOSS does not have because exiting/forking is far less damaging (at the same time this is not a 'network' in Powell's terms because identities are not fixed and membership is volatile);

- Its low control intensity does not apply because, even if it remains true that blockchain software can be easily modified as any other FOSS, those changes are not relevant for authentication until they substitute the current software version run by miners and users;
- Thus, copyleft may affect but does not define blockchain-related governance and its capacity to mobilize human and technical resources, and also to commit them over long periods of time;

- Rather than as always under development product, blockchains are better conceptualized as a means of governance for what they authenticate and how.

These peculiar characteristics of blockchain governance, which diverges from the bazaar but does not fall back into Powell's threefold categorization substantiate our proposal for the 'tribal governance' idealtype. Reasons for referring to tribes are: they use to have their own mode of governance which is not defined by the rule of law and enforced by states within their territory; despite own rule, they use to interact with societies regulated by formal laws, whose territories they often cross; they have charismatic chiefs but the boundaries between inside and outside the tribe are often vague [57].

Tribal governance can be well illustrated by land registries. Swan [31], as much as our interviewees, are aware that deploying blockchains as reliable records for decades-long periods is not only a matter for software whose code is freely accessible in the future. In fact, providing the required time longevity of records is about ensuring from the beginning the persistence of a functioning consensus mechanism (including hashing power, stakes, etc. depending on the blockchain type). Needless to say, compromised records would be catastrophic for national land and real estate records, with so much of the economy anchored to them. In sum, trust needs to be built far beyond software itself and its code availability. In the cases of blockchains for land registries, faceless trust needs to relate to identifiable properties. Usually, notaries and state officers are in charge of it. This raises up the questions of liability: if there is no unique responsibility, who is liable when something goes wrong? The awareness of those risks manifests in the cases above, whose blockchains are both linked to Bitcoin's -by far the most reliable blockchain because its size and track record- and state records. However, this induces conflicts between modes of governance: trust in the crowd (or better in the 'tribe') may not align with trust in the state ('hierarchy'). If in 20 years an immutable blockchain records a different owner for a piece of land than an old paper certificate, what would a judge trust? What has legal standing?

Descending from this sort of problems, it catches the attention that bureaucracies -certainly a manifestation of hierarchical governance- are traditionally in charge of authentication. This raises the interesting question of how their functioning encounters and collides with blockchain tribal governance, which promises to perform the same function but relies on a possibly incompatible governance mode. Some of the aspects of this encounter emerge from the Estonian project of providing identity authentication also to non-Estonians, and even an own cryptocurrency Estcoin, rely- 
ing on blockchain [36]. The Estonian e-residency initiative [36] raises concerns regarding identity authentication and the possible consequences of displacing responsibilities. This is in line with the call for individual accountability [5, 6]. Our initial empirical work showed that the interactions between existing authorities and blockchain records are far from settled. For instance, there is no full scale and routinized land registration relying on blockchains. Rather, specific disputes are recorded on pilot blockchains in case they can help court cases. This is particularly interesting in countries based on the common law, where courts legislate through precedents.

Comparing bureaucracy and blockchain-based authentication, one can see remarkable differences. Especially important appear to be those about relying on private resources for providing a service of general interest (see Morabito [39]). It is certainly a concrete risk that, if in the future public and private interests diverged, there would be no mandate nor legal basis to force a faceless tribe of actors to act in the public interest. Since blockchain users, like skillful internet users more generally, may operate with some level of anonymity across jurisdictions, bureaucracies are in short of fit-for-purpose tools. Here the famous internet motto "We reject: kings, presidents and voting. We believe in: rough consensus and running code" points to a mode of governance of an open-ended aggregate of actors -rather than of a defined citizenry/body politic through consensus.

\section{Conclusion}

In our study, we propose and characterize a new type of governance - tribal governance, which emerges from adoption of blockchain technology.

In any case we should not be deterministic in assuming what decentralized architectures imply and require. Agre [58], referring to the previous wave of peerto-peer architectures originated with file sharing, instils the reasonable doubt that decentralized architectures do not necessarily match with decentralized institutions and vice versa. Especially, decentralization may not necessarily lead to equality in practice. In fact, most open projects (like the Web, Wikipedia, P2P, FOSS) showed remarkable tendencies to centralization over time [59]. This is certainly possible for blockchain and, for instance, Bitcoin mining shows a clear centralization in China where estimates place $2 / 3$ of computing power.

Also, following our criticism of overemphasis on algorithms alone, 'Code is law' - echoing Lessig's book [60] - may not to apply to law in the traditional sense of defining what is right or wrong. Long-term consequences in governance remain largely unpredictable, especially where state authorities cannot be taken for granted. In prospect, reliable records promise to ex- clude unreliable authorities, thus reallocating elsewhere some traditional functions of hierarchies, markets and networks.

\section{References}

1. Williamson, O.E.: The Economic Intstitutions of Capitalism. Simon and Schuster (1985).

2. Powell, W.W.: NEITHER MARKET NOR HIERARCHY. Research in Organizational Behavior. 12, 295-336 (1990).

3. Demil, B., Lecocq, X.: Neither market nor hierarchy nor network: The emergence of bazaar governance. Organization Studies. 27, 1447-1466 (2006).

4. Zittrain, J.L.: The generative internet. Harvard Law Review. 1974-2040 (2006).

5. Ghassan O. Karame, E.A., Marc Roeschlin, Arthur Gervais, Srdjan ÄEapkun: Misbehavior in Bitcoin: A Study of Double-Spending and Accountability. ACM Transactions on Information and System Security (TISSEC). (2015).

6. Raiborn, C./ S., Marcos: Accounting Issues Related to Bitcoins. Journal of Corporate Accounting \& Finance. (2015).

7. Reijers, W., O’Brolcháin, F., Haynes, P.: Governance in Blockchain Technologies \& Social Contract Theories. Ledger. 1, 134-151 (2016).

8. Loh, L., Venkatraman, N.: Diffusion of information technology outsourcing: influence sources and the Kodak effect. Alfred P. Sloan School of Management, Massachusetts Institute of Technology. (1992).

9. Henderson, J.C., Venkatraman, N.: Strategic alignment: Leveraging information technology for transforming organizations. IBM systems journal. 32, 4-16 (1993) 10. Brown, C.V.: Examining the emergence of hybrid IS governance solutions: Evidence from a single case site. Information Systems Research. 8, 69 (1997).

11. Sambamurthy, V., Zmud, R.W.: Arrangements for information technology governance: A theory of multiple contingencies. Mis Quarterly. 23, 261-290 (1999).

12. Weill, P., Broadbent, M.: Leveraging the new infrastructure: how market leaders capitalize on information technology. Harvard Business Press (1998).

13. Weill, P., Ross, J.W.: IT Governance: How Top Performers Manage IT Decision Rights for Superior Results Harvard Business Press (2004).

14. Musiani, F., Cogburn, D.L., DeNardis, L., Levinson, N.S.: The Turn to Infrastructure in Internet Governance. Springer (2016).

15. Williamson, O.E.: Strategy Research: Governance and Competence Perspectives. Strategic Management Journal. 20, 1087-1108 (1999).

16. Williamson, O.E.: Markets and Hierarchies: Analysis and Antitrust Implications: A Study in the Economics of Internal Organization. Social Science Research Network, Rochester, NY (1975).

17. Watson, R.T., Boudreau, M.-C., Greiner, M., Wynn, D., York, P., Gul, R.: Governance and global communities. Journal of International Management. 11, 125-142 (2005).

18. Surowiecki, J.: The wisdom of crowds. Random House Digital, Inc. (2005).

19. Raymond, E.: The cathedral and the bazaar. Know Techn Pol. 12, 23-49 (1999).

20. Krogh, G.V., Haefliger, S., Spaeth, S., Wallin, M.W.: Carrots and Rainbows: Motivation and Social Practice in 
Open Source Software Development. MIS Quarterly. 36, 649-676 (2012).

21. DuPont, Q.: Experiments in algorithmic governance: A history and ethnography of "The DAO," a failed decentralized autonomous organization. Bitcoin and Beyond: Cryptocurrencies, Blockchains and Global Governance. Routledge. (2017).

22. Lucas, H.C., Goh, J.M.: Disruptive technology: How Kodak missed the digital photography revolution. The Journal of Strategic Information Systems. 18, 46-55 (2009).

23. Garud, R., Munir, K.: From transaction to transformation costs: The case of Polaroid's SX-70 camera. Research Policy. 37, 690-705 (2008).

24. Dyer, J.H., Chu, W.: The Role of Trustworthiness in Reducing Transaction Costs and Improving Performance: Empirical Evidence from the United States, Japan, and Korea. Organization Science. 14, 57-68 (2003). 25. Gambetta, D.: Trust: Making and Breaking Cooperative Relations. Blackwell (1988).

26. Lustig, C., Nardi, B.: Algorithmic authority: The case of Bitcoin. Presented at the System Sciences (HICSS), 2015 48th Hawaii International Conference on (2015). 27. Brown, P., Calnan, M.: Braving a faceless new world? Conceptualizing trust in the pharmaceutical industry and its products. Health: 16, 57-75 (2012).

28. Beldad, A., De Jong, M., Steehouder, M.: How shall I trust the faceless and the intangible? A literature review on the antecedents of online trust. Computers in Human Behavior. 26, 857-869 (2010).

29. Benkler, Y.: The wealth of networks: How social production transforms markets and freedom. (2006). 30. Maurer, B., Nelms, T.C., Swartz, L.: "When perhaps the real problem is money itself!": the practical materiality of Bitcoin. Social Semiotics. 23, 261-277 (2013). 31. Swan, M.: Blockchain: Blueprint for a New Economy. O'Reilly Media, Inc. (2015).

32. Nakamoto, S.: Bitcoin: A peer-to-peer electronic cash system. Consulted. 1, 2012 (2008).

33. Dodd, N.: The social life of Bitcoin. Theory, Culture \& Society. (2017)

34. Atzori, M.: Blockchain technology and decentralized governance: Is the state still necessary? (2015). 35. MacDonald, T.J., Allen, D.W.E., Potts, J.: Blockchains and the boundaries of self-organized economies: Predictions for the future of banking. New Economic Windows. 279-296 (2016).

36. Sullivan, C., Burger, E.: E-residency and blockchain. Computer Law \& Security Review. (2017).

37. Quinn DuPont and Bill Maurer: Ledgers and Law in the Blockchain. Kings Review. (2015).

38. Walsh, C., OReilly, P., Gleasure, R., Feller, J., Li, S., Cristoforo, J.: New kid on the block: a strategic archetypes approach to understanding the Blockchain. (2016). 39. Morabito, V.: Business Innovation Through Blockchain. Springer International Publishing, Cham (2017). 40. Ekblaw, A., Azaria, A., Halamka, J.D., Lippman, A.: A Case Study for Blockchain in Healthcare:"MedRec" prototype for electronic health records and medical research data. (2016).

41. Marcel Morisse: Cryptocurrencies and Bitcoin: Charting the Research Landscape. University of Hamburg. (2015).

42. Herbert, J., Litchfield, A.: A Novel Method for Decentralised Peer-to-peer Software License Validation Using Cryptocurrency Blockchain Technology. Presented at the 38th Australasian Computer Science Conference January 27 (2015).

43. Briggs, R.O., Schwabe, G.: On Expanding the Scope of Design Science in IS Research. In: Service-Oriented Perspectives in Design Science Research. pp. 92-106. Springer, Berlin, Heidelberg (2011).

44. Stebbins, R.A.: Exploratory Research in the Social Sciences. SAGE (2001).

45. Hutt, R.: Beyond bitcoin: 4 surprising uses for blockchain, https://www.weforum.org/agenda/2016/12/fighting-human-traffickingtracing-blood-diamonds-and-other-surprising-uses-forblockchain/.

46. Aitken, R.: Bitland's African Blockchain Initiative Putting Land On The Ledger, http://www.forbes.com/sites/rogeraitken/2016/04/05/bitlands-african-blockchain-initiative-putting-land-on-theledger/.

47. Bates, C.: Bitland Global, https://bravenewcoin.com/assets/Whitepapers/Bitland-Whitepaper.pdf, (2016).

48. Rizzo, P.: Blockchain Land Title Project "Stalls" in Honduras, http://www.coindesk.com/debate-factomland-title-honduras/.

49. Bandeira, P., Sumpsi, J.M., Falconi, C.: Evaluating land administration systems: A comparative method with an application to Peru and Honduras. Land Use Policy. 27, 351-363 (2010).

50. Snow, P., Deery, B., Lu, J., Johnston, D., Kirby, P., Sprague, A.Y., Byington, D.: Business processes secured by immutable audit trails on the blockchain. (2014).

51. Keane, J.: Sweden Moves to Next Stage With Blockchain Land Registry, http://www.coindesk.com/swedenmoves-next-stage-blockchain-land-registry/.

52. Mizrahi, A.: A blockchain-based property ownership recording system, https://chromaway.com/papers/Ablockchain-based-property-registry.pdf.

53. Kempe, M.: The Land Registry in the blockchain, http://ica-it.org/pdf/Blockchain_Landregistry_Report.pdf, (2016).

54. Shin, L.: Republic Of Georgia To Pilot Land Titling On Blockchain With Economist Hernando De Soto, BitFury,

http://www.forbes.com/sites/laurashin/2016/04/21/republic-of-georgia-to-pilot-land-titling-on-blockchain-witheconomist-hernando-de-soto-bitfury/.

55. Pipan, R.: The Bitfury Group and Government of Republic of Georgia Expand Historic Blockchain Land-Titling Project, http://bitfury.com/content/4press/the_bitfury_group_republic_of_georgia_expand_blockchain_pilot_2_7_16.pdf, (2016).

56. Victoria Louise Lemieux: Trusting records: is Blockchain technology the answer? Records Management Journal. 26, 110-139 (2016).

57. Bodley, J.H.: Cultural Anthropology: Tribes, States, and the Global System. Rowman Altamira (2011).

58. Agre, P.E.: P2p and the promise of internet equality. Communications of the ACM. 46, 39-42 (2003). 59. O'Mahony, S., Ferraro, F.: The emergence of governance in an open source community. Academy of Management Journal. 50, 1079-1106 (2007).

60. Lessig, L.: Code and Other Laws of Cyberspace. Basic Books (1999). 